\title{
Optimization of a Slurry Dispersion Method for Minerals and Trace Elements Analysis in Infant Formulae by ICP OES and FAAS
}

\section{Cristina Sola-Larrañaga and Iñigo Navarro-Blasco}

\author{
University of Navarra, Faculty of Sciences, Department of Chemistry, Pamplona \\ (Navarra), E-31.080, Spain
}

\begin{abstract}
Infant formula developed by manufacturers requires a rigorous control of composition, particularly those elements added routinely in an attempt to mimic the mineral composition of human milk. A total of 97 different types of powdered infant formulae (preterm, adapted starter, adapted follow-up, toddler, specialised and soy based formulae) commercially available in Spain were studied. It is noteworthy great differences in mineral (Ca, $\mathrm{P}, \mathrm{Mg}$ ) and trace element ( $\mathrm{Zn}, \mathrm{Fe}, \mathrm{Cu}, \mathrm{Mn}$ ) contents found between analysed and listed in label information. The development of a fast, simple and direct slurry method for the determination of these essential micronutrients in infant formula by inductively coupled plasma optical emission spectrometry (ICP OES) and flame atomic absorption spectrometry (FAAS) was performed in order to help in quality control tasks. Infant formula samples were solubilised using different amounts of several different solvents. An addition of $250 \mu \mathrm{L}$ of a solution $10 \%$ tetramethylammonium hydroxide and $25 \%$ ammonium hydroxide were required for the accurate quantification of $\mathrm{Ca}$ and $\mathrm{P}, \mathrm{Mg}, \mathrm{Zn}, \mathrm{Fe}, \mathrm{Cu}$ and $\mathrm{Mn}$, respectively. The standard reference material 1549 non-fat milk powder was solubilised to compare the validity of assayed methodology following slurry nebulisation and traditional microwave-assisted acid digestion method. Good agreement of the analytical results by both ICP OES and FAAS, with the certified values was obtained. Method performance parameters (accuracy, precision and methodological detection limits) were determined for studied elements to check the quality and usefulness of the optimised slurry method. The analytical procedure was applied successfully to the analysis of a representative group of infant formulae. Levels of analysed elements were graphically represented, showing an acceptable comparability between slurry and acid-mineralisation method set by linear correlation coefficients and slopes close to the unit. The described simple and slurry method is appropriate, as an attractive alternative, for routine control analysis of added essential elements in infant formulae regardless of predominant protein type used in manufacture.
\end{abstract}

Keywords: Inductively coupled plasma optical emission spectrometry (ICP OES); flame atomic absorption spectrometry (FAAS); slurry; infant formula; minerals; trace elements. 


\section{Introduction}

Proper nutrition is particularly critical during infancy when growth and development are most rapid and therefore, the consequences of inadequate nutrition are most severe. Breast milk is the most adequate food for babies, but in some cases it is not sufficient to feed up the infant and the infant formula use is imperative (Delagne \& West, 2003). Likewise, infant formulae are manufactured by modifying cow milk composition so as to resemble that of human milk. It involves mainly an adaptation of the total levels of protein, fat, carbohydrates and minerals in cow milk. Most formulae are based on whole or skim milk with or without demineralised whey, vegetable oils or vegetable oils-milk fat mixtures, and added vitamins and trace elements. Optimal growth and development of infants may be guaranteed when both, food and water intakes provides the required doses of all essential (major and minor) elements and delivers only ineffectual concentration of potentially toxic elements. The adjustment of electrolytes and major minerals content of infant formulae has become the most sophisticated step manufacturing. Main electrolytes (sodium and potassium) and major elements (calcium, phosphorous and magnesium) contained at high levels in cow milk, must be reduced by means of electrodialysis ion exchange or/and ultrafiltration in the standardization process to obtain a minor level of these minerals, which consumed by infants at high concentrations could lead to renal overcharge, calcifications and bone demineralisation (World Health Organization \& Food and Agricultural Organization, 2004). Membrane technology is now well established and has widespread use in the dairy industry. During the ultrafiltration process, fat and proteins are retained; thus those elements partly or wholly bound to protein are also removed. In reverse osmosis, theoretically all components other than water are separated, but in practice a very small loss of certain elements (calcium, magnesium and phosphorous) occurs. In short, the dynamic equilibrium of mineral components between aqueous and colloidal phases of milk is affected (Scott, 1989). It brings about partial replacement of all the minerals removed which must be added under inorganic salts in an attempt to mimic the mineral composition of human milk. Moreover, during these treatments others minor elements are also removed and as a consequence these essential micronutrients are normally added to infant formula at higher level than that which are present in human milk in order to compensate its lower bioavailability. Usually no remark is made for the intrinsic trace element content of the formula ingredients and actual contents show normally wide different in comparison with those values that label claims. 
From the chemical point of view, infant formula is essentially a suspension of proteins, homogenised oils and sparingly soluble minerals in a solution of carbohydrates and minor ingredients. Thus, these formulations are a complex matrix offering significant challenge to the analyst. Industry analysts have usually used several techniques for mineral and trace elements determinations in infant formula, among others flame or graphite furnace atomic absorption spectrometry (FAAS, GF AAS), inductively coupled plasma optical emission spectrometry (ICP OES) or mass spectrometry (ICP MS). Most element quantification procedures are usually performed in solution. Traditional mineralization in order to destroy the organic matter is the most critical step during analysis. Digestion in a closed vessel with pressure control and microwave heating is often recommended to avoid any contamination and to increase the sample throughput rate.

Subsequently, alternative methods to the conventional acid attack based on slurries or extract improve inherent advantage of required time, speed and ease of analysis, and are readily adapted to repetitive analysis of relatively large numbers of samples with a minimised risk of potential losses or contamination. Thus, some simple and attractive dissolution methods have been developed for several matrices (Nóbrega, Santos, de Sousa, Cadore, Barnes \& Tatro, 2006). Nóbrega, Gélinas, Krushevska and Barnes (1997) have proposed the use of tertiary amine and etilendiaminetetracetic acid (EDTA) for biological and dairy materials by ICP MS. Thixotropic agent (Triton X-100) were applied to determination of mineral elements (Ca, Mg, K, Na and Zn) in milk samples by means of ICP OES (Murcia, Vera, Martínez-Tomé, Muñoz, Hernández-Córdoba \& Ortiz-González, 1999; McKinstry, Indyk \& Kim, 1999). Although, in case of certain milk products, the attempt to determine $\mathrm{Ca}, \mathrm{P}, \mathrm{Mg}$ and $\mathrm{Zn}$, by direct aqueous slurry nebulization was failed (Hua, Kay \& Indyk, 2000). Slurry sampling offers several benefits to the analysis of trace elements in different types of samples by GF AAS or electrothermal vaporization ICP MS, demonstrated in several literature reports (Campillo, Viñas, López-García, \& Hernández-Córdoba, 1998; Pozebon, Dressler \& Curtius, 1998; Miller-Ihli, 1997). Also, the sample dispersion in tetramethylammonium hydroxide (TMAH) was investigated (Matusiewicz, \& Golik, 2004, Ribeiro, Moretto, Arruda \& Cadore, 2003; Martins, Pozebon, Dressler \& Kemieciki, 2002; Stürup \& Buchert, 1996).

In short, infant formula developed by manufacturers requires a rigorous control of composition with special concern related to minerals and trace elements, particularly 
those elements added routinely. Thereby, the tune-up of a direct, fast and low cost methodology represents a clear interest for the quality control operations of these essential micronutrients in this kind of matrices to the dairy sector manufacturers.

This paper shows the substantial differences between the values of mineral and trace elements measured and those indicated on the label information of infant formula sold commercially in Spain. To solve this difficulty, it was developed a simple dispersion methodology, evaluating different solvents, for the determination of $\mathrm{Ca}, \mathrm{P} \mathrm{Mg}, \mathrm{Fe}, \mathrm{Zn}$, $\mathrm{Cu}$ and $\mathrm{Mn}$ in different types if infant formulae by ICP OES with conventional pneumatic nebulisation, taking into account its good performance, multielement ability and great linear dynamic range and FAAS, chosen for good reproducibility, easiness and quickness analysis and reasonable precision for quality control in integrated laboratories programs rather than other instrumental techniques listed above (Bermejo, Domínguez \& Bermejo, 1997). Also, in order to compare the validity and versatility of dispersion analysis following slurry nebulization and traditional microwave-assisted acid digestion method, the analysis of a standard reference material was carried out. The method was applied to real samples to establish its accuracy by comparing with pressured microwave-assisted digestion method.

\section{Experimental}

\subsection{Apparatus and experimental conditions}

A Perkin Elmer Aanalyst 800 atomic absorption spectrometer equipped with a stainless steel nebulizer and impact bead, and deuterium lamp as a background correction system was used. Assays by FAAS were performed at 422.7, 285.2, 213.9, 248.3, 324.8 and 279.5 nm for Ca, Mg, Zn, Fe, Cu and Mn, respectively. Hollow cathode lamps operated at $20,20,15,30,15$ and $20 \mathrm{~mA}$ and bandwidths of $0.7,0.7,0.7,0.2,0.2$ and $0.2 \mathrm{~nm}$ for each element listed above. An air/acetylene flame was used.

A Jobin-Ybon JY38S Plus ICP OES spectrometer powered by a $40.68 \mathrm{MHz}$ radiofrequenzy generator at 1400 watts was used for elemental determination. This instrument operates in the sequential measurement mode (radial measurements) and has a Czerny-Turner mounting with a 2400 grooves $\mathrm{mm}^{-1}$ holographic plane grating, the focal length is $1 \mathrm{~m}$. The main argon flow was $12 \mathrm{~L} \mathrm{~min}^{-1}$, and the cooling flow $0.45 \mathrm{~L}$ $\min ^{-1}$. The nebulizer was a Meinhard type with Scott concentric nebulization chamber, operated at 34 psi, with argon aerosol gas and a $0.6 \mathrm{~L} \mathrm{~min}^{-1}$ flow-rate. Sample aspiration was forced by means of a Spetec Perimax 12 peristaltic pump with a $1.4 \mathrm{~mL} \mathrm{~min}^{-1}$ 
sample delivery rate. The analytical lines (type of spectral line and the integration times) used for the different elements were: Ca, $317.933 \mathrm{~nm}$ (II, 0.5 s); Mg, $383.231 \mathrm{~nm}$ (I, 0.5 s); P, 213.618 nm (I, 1.0 s); Fe, 259.940 nm (II, 0.5 s); Zn, 213.856 nm (I, 0.5 s); Cu, 324.754 nm (I, 0.5 s); Mn, 257.610 nm (II, 0.5 s). Nebulizer clogging was avoided by using suitable uptake and rinsing cycles. A 30 s pre-observation aspiration time and a 30 s rinse time with ultrapure deionised water were applied. Warm-up time (plasma on) was $30 \mathrm{~min}$.

Mineralization of infant formulae and certified reference material for comparison purposes was carried out in PTFE closed vessels using Ethos Plus microwave labstation with computer easywave software (Millestone s.r.l., Sorisole, Italy).

A Transsonic 310 by Elma ultrasonic bath of $14 \mathrm{~W}$ constant power was used.

\subsection{Sample collection}

Infant formulae analyzed are commercially available in Spain. A total of 97 different powdered infant formulae from 9 different manufactures were studied. Both types, based on cow's milk ( $(\mathrm{=} 90)$ and soy-based formulae $(\mathrm{n}=7)$, were investigated. Cow's milk-based formulae included: preterm formula $(n=6)$, adapted starter formula $(n=$ 19), adapted follow-up formula $(\mathrm{n}=17)$, toddler formula $(\mathrm{n}=5)$ and specialised formula (hypoallergenic $(n=10)$, lactose-free $(n=10)$, designed to avoid regurgitation $(n=15)$ and functional type $(n=8)$ formula).

\subsection{Reagents}

Exclusively, high-quality water (ultrapure deionised water type Milli Q, resistivity 18.1 $\mathrm{M} \Omega \mathrm{cm}$ ) was used for preparation and/or dilution of treated sample and standard solutions.

Individual stock standard solutions (1000 mg $\left.\mathrm{L}^{-1}\right)$ of investigated elements were obtained from Merck, Darmstadt (Germany). Before the analyses, calibration curves were made from multielemental working standards prepared daily by appropriate dilution of aqueous solutions of the elements analysed.

Concentrated 65\% nitric acid from Merck, Darmstadt (Germany) was further purified by sub-boiling distillation in a quartz still (Hans Kürner, Rossenheim, Germany).

Solutions $10 \%(\mathrm{w} / \mathrm{v})$ of Triton X-100 and Tetramethylammonium hydroxide pentahydrate, purchased from Sigma (Sigma-Aldrich Chemie, Steinheim, Germany); 
and tracepur $25 \%$ ammonium hydroxide (Merck, Darmstadt, Germany) were used to prepare the slurry samples for the dispersion method.

To overcome potential anionic interferences when determining calcium and magnesium by FAAS, mainly strong phosphate interference, the final samples and standards were diluted to contain $1 \%$ (w/v) lanthanum (as chloride, $\mathrm{LaCl}_{3} 7 \mathrm{H}_{2} \mathrm{O}$ Merck, Darmstadt, Germany).

Standard reference material non-fat milk powder SRM 1549 was obtained from the National Institute of Standards and Technology (NIST, USA).

\subsection{Analytical procedures}

\section{Microwave-assisted mineralization procedure}

Infant formula or standard material samples $(0.4000 \mathrm{~g})$ were placed into high-pressure Teflon bombs and treated with $7 \mathrm{~mL}$ of sub-boiling nitric acid in microwave labstation. The optimised microwave digestion programme applied included two steps: $25-170{ }^{\circ} \mathrm{C}$ for $10 \mathrm{~min}$. and $170{ }^{\circ} \mathrm{C}$ for $10 \mathrm{~min}$., both at $1000 \mathrm{~W}$, followed immediately by ventilation at room temperature. The acid digested sample solutions were made up to a final volume of $10 \mathrm{~mL}$ with ultrapure deionised water in a volumetric polyethylene flask. Samples were digested in triplicate.

Special care was adopted to avoid the contamination. Sample containers and other glassware were cleaned with metal-free non-ionic detergent solution (Triton X-100), rinsed three times with tap water, soaked in $10 \% \mathrm{HNO}_{3}$ acid for $24 \mathrm{~h}$ and then rinsed many times with ultrapure deionised water. All sample containers were rinsed again with deionised water prior to use. All handling and sample treatment operations were carried out using vinyl talc-free gloves.

Blanks, consisting of deionised water and sub-boiling nitric acid, were subjected to a similar sample preparation and analytical procedure.

\subsection{Slurry dispersion procedure}

For dispersion method, $0.4000 \mathrm{~g}$ of powder infant formula or between $0.2000-0.3000 \mathrm{~g}$ of reference material were accurately weight, transferred to a volumetric polyethylene flask and dissolved up to $10 \mathrm{~mL}$ of aqueous solution containing assayed solvents (ultrapure water, triton $\mathrm{X}-100$, TMAH or $\mathrm{NH}_{4} \mathrm{OH}$ ), added in different serial experiments from 25 to $500 \mu \mathrm{L}$. The suspensions were sonicated for a few minutes (2-5 min.) to ensure the absence of lumps. The effect of both, different solvent and added volume, 
was tested. The certified reference material SRM non-fat milk powder 1549 was chosen to evaluate the efficiency of different solvents assayed for dissolving dairy samples. Slurry sampling minimizes the time required for sample preparation and the risk of contamination resulting from reduced sample manipulation. Each sample was prepared by triplicate.

Blanks were processed through an identical procedure.

\subsection{Measurements}

Obtained solutions in both methods were analyzed by ICP OES and FAAS, using operating and experimental conditions related above, for confirming the reliability of the slurry procedure.

Calibrations were accomplished using direct calibration against aqueous standard. Two reagent blanks and an aqueous internal standard and ten samples were included in each analytical batch to provide an on-going quality control information. Background corrections were applied to sample results. Measurements were repeated at least three times, and the results presented show the average of the concentrations obtained of triplicate assay.

\section{Results and discussion}

\subsection{Manufacturer and analysed values of mineral and trace elements}

Infant formulae have a special role to play in the feeding of unweaned baby because they are often the only or the predominant source of essential nutrients for many infants. This fact implies that the composition of commercial formulae must be carefully controlled in order to meet the nutrient requirements set by EEC legislation in force. Manufacturers set mineral and trace element levels for their label claims that are generally above the minimum specification, adding these micronutrients at a higher level than at which they are present in human milk.

In this respect, it is noteworthy great differences in mineral and trace element contents found between analysed and those values provided in labelling information by manufacturers, as is shows in Fig. 1. Sodium and potassium concentrations were generally similar or a bit lower than those indicated in the label. The efficient methods used for reducing the mineral content of whey or cow milk during the first stage of standardization, provide a proper control of both electrolytes. 
In contrast, calcium, phosphorous and magnesium contents supplied by infant formulae studied was higher than those claimed by manufacturers. Probably manufacturers have not taken into account the seasonal variations, lactating stage and physicochemical changes as a result of handling, treatment or processing and storage which affect the mineral composition of cow milk and at the same time, the intrinsic mineral content of other raw materials used in the manufacture of adapted infant formula. Calcium and phosphorous are usually added to infant formula in standardization step to reach an optimal ratio between 1.5 and 2:1 in order to achieve an adequate mineral intake. Likewise, magnesium salts are added due to the lower bioavailability.

Regarding trace elements, it is also recognized that are less bioavailable from infant formula than from human milk (Lönnerdal, 1991). Consequently, these micronutrients are added at a higher level than at which are present in human milk. Iron, zinc, copper and manganese are all added by means of an approved inorganic salt. Usually no allowance is made for the intrinsic trace element content of the formulae ingredients and actual contents are normally higher than labels claim. In our study, this fact is proved in iron and zinc analyzed values, whereas manganese and copper contents exhibited large variations but similar between analyzed and label levels (Fig. 1). These findings show up the need for providing procedures of quality control and good manufacturing practices in order to control the mineral (Ca, P, Mg) and trace elements (Fe, $\mathrm{Zn}, \mathrm{Cu}$, $\mathrm{Mn}$ ) levels which are varying according to the raw material used by manufacturers.

\subsection{Preliminary analytical studies}

Preliminary experiments were focused on obtaining suitable suspension of infant formulae. Several chemicals (ultrapure water, triton $\mathrm{X}-100$, TMAH and $\mathrm{NH}_{4} \mathrm{OH}$ ) were tried with the aim of obtaining a clear slurry with good characteristics of dispersion, homogeneity and stability. Analytical determinations were carried out by ICP OES using the reference material SRM 1549.

Firstly, we ruled out the idea of using ultrapure water. After sonication, lumps were presented. Triton X-100 solvent was scrapped because ICP OES nebulisation was not good, also provided problematic due to foam. In this respect, dairy products analysis by direct nebulisation of aqueous solutions has been reported to be compromised by poor accuracy attributed both aerosol droplet size and fatty acid content, resulting incomplete elemental quantification (Coni, Stacchini, Caroli \& Falconieri, 1990; Emmett, 1988). 
However, several works have emphasised the proper dissolution of milk samples in alkaline medium to prevent protein precipitation (Stürup \& Buchert, 1996; Matusiewicz \& Golik, 2004). Besides, it is known that TMAH is an efficient reagent to solubilise tissues samples. TMAH reaction with them is perceptible through foam formation, viscosity and odour resembling an esterification reaction and soap formation. After this, additions of different volumes of TMAH or $\mathrm{NH}_{4} \mathrm{OH}$ were tried (25-500 $\left.\mu \mathrm{L}\right)$.

In a second step, ultrasonic agitation was applied because of its potential to accelerate the solubilisation process. Therefore, the use of sonication was considered to reduce the time required for alkaline solubilisation. It was checked that ultrasonic probe during 2-5 minutes provided a better stirring than vortex mixing or magnetic agitation and at the same time, an increase of solubilisation rate is achieved in order to enhance simplicity and to reduce the time consumption of methodology.

Before analyzing sample dispersions, blanks were determined to evaluate the possible sources of contamination. In this sense, according with purity considerations, solubilisation reagents are the major source of the blank, because handling and sample treatment was carried out under flow laminar bench, using vinyl talc free gloves and following a strict protocol of trace analysis. No significant contribution of the studied element to blanks was found from reagents and treatment procedure.

At this point, sample suspensions were assayed and quantified by ICP OES. The optimal calcium quantification was achieved by addition of $250 \mu \mathrm{L}$ of $10 \%$ TMAH. Found concentration was $12.98 \pm 0.22 \mathrm{mg} \mathrm{g}^{-1}$, included in certified range of SRM 1549 $\left(13.0 \pm 0.5 \mathrm{mg} \mathrm{g}^{-1}\right)$. The determination of the other elements $\left(\mathrm{P}, 10.70 \pm 0.15 \mathrm{mg} \mathrm{g}^{-1}\right.$; Mg, $1.222 \pm 0.013 \mathrm{mg} \mathrm{g}^{-1} ; \mathrm{Zn}, 43.93 \pm 0.01 \mu \mathrm{g} \mathrm{g}^{-1}$; Fe, $1.74 \pm 0.09 \mu \mathrm{g} \mathrm{g}^{-1}$; Cu, $0.653 \pm$ $0.012 \mu \mathrm{g} \mathrm{g}^{-1}$; and $\mathrm{Mn}, 0.303 \pm 0.002 \mu \mathrm{g} \mathrm{g}^{-1}$ ) was found to be adequate when the same volume of $25 \% \mathrm{NH}_{4} \mathrm{OH}$ was added (certified interval of reference material: $10.6 \pm 0.2$ $\mathrm{mg} \mathrm{g}^{-1} ; 1.20 \pm 0.03 \mathrm{mg} \mathrm{g}^{-1} ; 46.1 \pm 2.2 \mu \mathrm{g} \mathrm{g}^{-1} ; 1.78 \pm 0.10 \mu \mathrm{g} \mathrm{g}^{-1} ; 0.7 \pm 0.1 \mu \mathrm{g} \mathrm{g}^{-1} ; 0.26$ $\pm 0.06 \mu \mathrm{g} \mathrm{g}^{-1}$ for $\mathrm{P}, \mathrm{Mg}, \mathrm{Zn}, \mathrm{Fe}, \mathrm{Cu}$ and $\mathrm{Mn}$, respectively).

In order to test the accuracy of the proposed methodology, SRM 1549 suspensions under the above experimental conditions were measured. A statistical test was applied for comparison of found and certified values (t-student test). It is possible to conclude that concentrations measured (slurry dispersion and acid-decomposition methods) do not differ significantly and comparable results with certified values were obtained. Furthermore, the concentrations obtained from SRM1549 suspensions by both methods 
agree well with certified values (Table 1). No statistical differences were found between determined and reference values at the $95 \%$ confidence limit.

In fact, additional comparative results against both acid mineralization and suspension method by ICP OES, were obtained for all assayed elements when slurries were measured by FAAS. Obtained data demonstrate both comparability for SRM 1549 declared values and good agreement in results for the analyzed elements by FAAS and ICP OES (Table 1).

In addition, an estimation of analyte recovery were performed by spiking the SRM 1549 slurries $(n=6)$ at the same levels of elements found previously. Calculations are also listed in Table 1. Recoveries were ranged in 98-102 \% and 97-103 \% by ICP OES and FAAS, respectively.

Sample blanks, containing all reagents were subjected to a similar sample preparation and analytical method as mentioned previously. Both, methodological detection (LOD) and quantification (LOQ) limits for each studied element using slurry and acid microwave digestion procedures, under the recommended conditions, were estimated and summarised in Table 2. Methodological limit was established based on three times the blank assay standard deviation and expressed in infant formula term (mg $100 \mathrm{~g}^{-1}$ powder infant formula as sold), following de IUPAC criteria. By comparing, aciddecomposition method provides a better detection limits, although in most cases are almost of the same order of magnitude. This fact is attributed to the different characteristics of high purity in the blank solutions, consisted of TMAH (reagent that can not easily be obtained in high purity) or ammonium hydroxide solutions and subboiling nitric acid for slurry dispersion and acid digestion methods respectively, resulting in different limits of detection. In this sense, it is noteworthy the large difference found in LOD value for zinc which may be caused by the high efficiency of subboiling distillation (considered as the best method of purification available for preparing high-purity inorganic acids) to remove this impurity (Mitchell, 1982; Kuehner, Alvarez, Paulsen \& Murphy, 1972).

This inconvenient may be overcome by increasing the initial weight of sample or decreasing the volume of final dilution with higher concentration (e.g. $25 \%$ w/w) of alkaline solvent, resulting in better LODs (Ribeiro et al., 2003). The estimated LODs were compared with those obtained in the literature by TMAH solubilisation (Matusiewicz \& Golik, 2004; Ribeiro et al., 2003). Globally slightly higher LODs, in most of the cases, were found compared to those calculated using direct slurry 
nebulisation in microwave induced plasma optical emission spectrometry (Matusiewicz \& Golik, 2004).

Nevertheless, the blank signals were not decisive since concentration levels of elements analyzed in infant formulae samples are mostly higher than LOQ values except in the case of manganese where certain non-supplemented formulae contain the lowest levels below LOQ but always included in detection analytical region. In spite of this concentration interval represents an area of less-certain quantification, it was considered suitable reporting these values exactly as it is stated in IUPAC recommendations (Currie, 1999).

Finally, the instrumental precision of both slurry dispersion and acid decomposition methods estimated from six consecutive determinations of the same infant formula (Hero Baby $1^{\circledR}$ ) was also listed in Table 2. The relative standard deviations determined in the intra-assay precision (aliquots of SRM 1549 samples measured during the same assay session) for dispersion method were as follows, Ca: ICP OES 0.83 \%, FAAS 1.78 \%; P: ICP OES 1.15 \%; Mg: ICP OES 1.07 \%, FAAS 1.45 \%; Zn: ICP OES 0.83 \%, FAAS 1.96 \%; Fe: ICP OES 1.89 \%, FAAS $1.97 \%$; Cu: ICP OES 2.33 \%, FAAS 4.34 \%; and Mn: ICP OES 2.29 \%, FAAS $5.34 \%$. These values are slightly lower than those calculated for the inter-assay (aliquots of SRM 1549 samples measured on different days), Ca: ICP OES 1.29 \%, FAAS 2.95 \%; P: ICP OES 2.90 \%; Mg: ICP OES 2.30 \%, FAAS 3.69 \%; Zn: ICP OES 2.30 \%, FAAS 3.35 \%; Fe: ICP OES 3.36 \%, FAAS 4.16 \%; Cu: ICP OES 4.40 \%, FAAS 7.36 \%; and Mn: ICP OES 5.20 \%, FAAS $9.09 \%$.

In general, it is possible to conclude that data show comparability of slurry dispersion (ICP OES and FAAS) with pressurized microwave-assisted acid decomposition method. Additionally these findings strongly suggest that slurry-FAAS can be used as an alternative faster and quite simpler analytical method.

\subsection{Application and analytical results}

The methodology as described above, has been successfully applied to a wide range of different types of infant formulae, both cow's milk and soya based formulae. Suspensions were prepared with a representative group of 50 different powder infant formulae (based on cow milk - $\mathrm{n}=45$ - and soy-based - $\mathrm{n}=5$ - formulae), including all types commercialised in Spain. Cow milk based formulae included: preterm formula (n $=5)$, adapted starter formula $(n=10)$, adapted follow-up and toddler formulae $(n=10)$, 
and specialised formula (hypoallergenic $(n=5)$, lactose-free $(n=5)$, designed to avoid regurgitation ( $n=5)$ and functional type $(n=5)$ formulae).

Due to variable content of studied elements in infant formula, the wide linearity of the ICP OES relative to FAAS and the need of agreement in dilution factor to carry out a simultaneous analysis, slurry dispersion method by ICP OES for Ca, P and Mg measurements and FAAS for $\mathrm{Zn}, \mathrm{Fe}, \mathrm{Cu}$ and $\mathrm{Mn}$, was selected. Furthermore, it must be keep in mind that the main objective is to develop a simple procedure employing routine laboratory apparatus and minimum handling to avoid losses or contamination with a reduced time and effort.

Table 3 shows the experimental values for studied elements after acid digestion and proposed slurry methods. According to the paired t-student test for a confidence level of $95 \%$, the results obtained by both procedures are in agreement, meaning that the proposed methodology is also accurate for real samples. As expected the relative standard deviations were higher for the results using slurry preparation than those results after acid attack; but even so they were acceptable for quantification in a quality control program of infant formula manufacture.

Levels of different analysed elements in commercial infant formulae are graphically presented in Fig. 2. These graphs are showing the concentration values found by slurry dispersion and digestion method, used as a reference. In general, there was acceptable comparability between both analytical methods for all analysed elements, pointed out by linear correlation coefficients, ranged from 0.9879 for $\mathrm{Mg}$ to 0.8527 for $\mathrm{Cu}$. Moreover, all graphics present slopes close to the unit (1.1359 for Ca and 0.9482 for $\mathrm{Cu}$ are extreme values but still near the ideal behaviour).

The proposed analytical procedure has demonstrated successful in the quantification of different types of infant formula, regardless of protein-based (cow's milk or soy) used in manufacture.

\section{Conclusions}

In spite of pressurized microwave-assisted digestion is a suitable methodology for sample preparation to analyze most of elements in food matrix by atomic techniques, it involves a time-consuming step (Cava-Montesinos, Cervera, Pastor \& de la Guardia, 2005). The used methodology introduces an attractive alternative for analysis of studied essential elements in raw material. The slurry dispersion methodology as described, allows successfully a faster and easier analysis of all types of infant formulae, with 
both, low cost and difficulty and the same reliability compared with acid-digestion method by assayed analytical techniques (ICP OES, FAAS). Sample preparation and handling is very simple requiring small amounts of reagents and a widely used technique (FAAS), suitable for the vast majority of quality control laboratories. Thus, the assayed methodology is evidently applicable to analyse frequently or routinely the raw or finished products in the manufacture of infant formulae.

\section{Acknowledgements}

This study was funded by the Departamento de Industria y Tecnología, Comercio, Turismo y Trabajo, Gobierno de Navarra and the Fundación Universitaria de Navarra (FUNA); Infant formulae were supplied by the companies: Abbott, Alter, Chiesi, Mead Johnson, Miltina, Milupa, Nestlé, Novartis, Nutricia and Ordesa. This support is gratefully acknowledged by the authors.

\section{References}

Bermejo, P., Domínguez, R., \& Bermejo, A. (1997), Direct determination of Fe and Zn in different components of cow milk by FAAS with a high performance nebulizer. Talanta, 45, 325-330.

Campillo, N., Viñas, P., López-García, I., \& Hernández-Córdoba, M. (1998), Direct determination of copper and zinc in cow milk, human milk and infant formula samples using electrothermal atomization atomic absorption spectrometry. Talanta, 46, 615-622.

Cava-Montesinos, P., Cervera, M.L., Pastor., A., \& de la Guardia, M. (2005), Room temperature acid sonication ICP-MS multielemental analysis of milk. Analytica Chimica Acta, 531, 111-123.

Coni, E., Stacchini, A., Caroli, S., \& Falconieri, P.J. (1990), Analytical approach to obtaining reference values for minor and trace elements in human milk. Journal of Analytical Atomic Spectrometry, 3, 581-586.

Currie, L.A. (1999), Detection and quantification limits: origins and historical overviews. Analytica Chimica Acta, 391, 127-134.

Delagne, F.M., \& West, K.P. (2003). Micronutrients deficiencies in the first months of life. Nestle Nutrition Workshop Series Pediatric Program, vol. 52. Basel: Karger.

Emmett, S.E. (1988), Inter-Laboratory note. Analysis of liquid milk by inductively coupled plasma mass spectrometry. Journal of Analytical Atomic Spectrometry, 3, 1145-1146. 
Hua, K.M., Kay, M., \& Indyk, H.E. (2000), Nutritional element analysis in infant formulas by direct dispersion and inductively coupled plasma-optical emission spectrometry. Food Chemistry, 68, 463-470.

Kuehner, E.C., Alvarez, R., Paulsen, P.J., \& Murphy, T.J. (1972), Production and analysis of special high-purity acides purified by sub-boiling distillation. Analytical Chemistry, 44, 2050-2056.

Lönnerdal, B. (1991). Concentrations, compartmentation and bioavailability of trace elements in human milk and infant formula. In R.K. Chandra, Trace Elements in Nutrition of Children II. Nestle Nutrition Workshop Series Vol. 23 (pp. 153-171). New York: Raven Press.

Martins, P., Pozebon, D., Dressler, V.L., \& Kemieciki, G.A. (2002), Determination of trace elements in biological materials using tetramethylammonium hydroxide for sample preparation. Analytica Chimica Acta, 470, 195-204.

Matusiewicz, H., \& Golik, B. (2004), Determination of major and trace elements in biological materials by microwave induced plasma optical emission spectrometry (MIPOES) following tetramethylammonium hydroxide (TMAH) solubilisation. Microchemical Journal, 76, 23-29.

McKinstry, P.J., Indyk, H.E., \& Kim, N.D. (1999), The determination of major and minor elements in milk and infant formula by slurry nebulisation and inductively coupled plasma-optical emission spectrometry (ICP-OES). Food Chemistry, 65, 245252.

Miller-Ihli, N.J. (1997), Slurry Sampling Electrothermal Atomic Absorption Spectrometry: Results From the Second Phase of an International Collaborative Study. Journal of Analytical Atomic Spectrometry, 12, 205-212.

Mitchell, J.W. (1982), Purification of analytical reagents. Talanta, 29, 993-1002.

Murcia, M.A., Vera, A., Martínez-Tomé, M., Muñoz, A., Hernández-Córdoba, M., \& Ortiz-González, R. (1999), Fast determination of the Ca, Mg, K, Na and Zn contents in milk and nondairy imitation milk using ICP-AES without mineralization stage. Lebensmittel-Wissenschaft und-Technologie, 32, 175-179.

Nóbrega, J.A., Gélinas, Y., Krushevska, A., \& Barnes, R.M. (1997), Direct determination of major and trace elements in milk by inductively coupled plasma atomic emission and mass spectrometry. Journal of Analytical Atomic Spectrometry, 12, 1243-1246.

Nóbrega, J.A., Gélinas, Y., Krushevska, A., \& Barnes, R.M. (1997), Determination of elements in biological and botanical materials by inductively coupled plasma atomic emission and mass spectrometry after extraction with a tertiary amine reagent. Journal of Analytical Atomic Spectrometry, 12, 1239-1242.

Nóbrega, J.A., Santos, M.C., de Sousa, R.A., Cadore, S., Barnes, R.M., \& Tatro, M. (2006), Sample preparation in alkaline media. Spectrochimica Acta Part B, 61, 465-495. 
Pozebon, D., Dressler, V.L., \& Curtius, A.J. (1998), Determination of trace elements in biological materials by ETV-ICP-MS after dissolution or slurry formation with tetramethylammonium hydroxide. Journal of Analytical Atomic Spectrometry, 13, 11011105.

Ribeiro, A.S., Moretto, A.L., Arruda, M.A.Z., \& Cadore, S. (2003), Analysis of Powdered Coffee and Milk by ICP OES after Sample Treatment with Tetramethylammonium Hydroxide. Microchimica Acta, 141, 149-155.

Scott, K.J. (1989). Micronutrients in milk products. In E. Renner, Micronutrients in milk and milk-based food products (pp. 71-123). London: Elsevier Science Publishers Ltd.

Stürup, S., \& Buchert, A. (1996), Direct determination of copper and iodine in milk and milk powder in alkaline solution by flow injection inductively coupled plasma mass spectrometry. Fresenius Journal of Analytical Chemistry, 354, 323-326.

World Health Organization, \& Food and Agricultural Organization (2004). Vitamin and mineral requirements in human nutrition. Geneva: World Health Organization. 
460 Figure 1. Box plot comparing minerals and trace elements levels contained 461 experimentally and labelled.

462

463 Figure 2. Mineral and trace elements levels found in different types of investigated 464 infant formula. Correlation of obtained results by acid-digestion and slurry dispersion 465 methods.

466 
Table 1. Values obtained for certified standard material and recovery results by both techniques (ICP OES and FAAS) following slurry dispersion or acid decomposition methods under the optimal conditions.

\begin{tabular}{lcccccc}
\hline \multirow{2}{*}{ Element } & $\begin{array}{c}\text { SRM 1549 } \\
\text { Certified values }\end{array}$ & $\begin{array}{c}\text { Digestion } \\
\text { ICP OES }\end{array}$ & ICP OES & Rec. \% & FAAS & Rec. \% \\
\hline $\boldsymbol{C a}\left(\mathrm{mg} \mathrm{g}^{-1}\right)$ & $13.0 \pm 0.5$ & $12.73 \pm 0.09$ & $12.98 \pm 0.22$ & $100 \pm 3$ & $12.85 \pm 0.07$ & $99 \pm 4$ \\
$\boldsymbol{P}\left(\mathrm{mg} \mathrm{g}^{-1}\right)$ & $10.6 \pm 0.2$ & $10.46 \pm 0.08$ & $10.70 \pm 0.15$ & $100 \pm 2$ & - & - \\
$\mathbf{M g}\left(\mathrm{mg} \mathrm{g}^{-1}\right)$ & $1.20 \pm 0.03$ & $1.215 \pm 0.050$ & $1.222 \pm 0.013$ & $100 \pm 4$ & $1.191 \pm 0.001$ & $99 \pm 4$ \\
$\mathbf{Z n}\left(\mu \mathrm{g} \mathrm{g}^{-1}\right)$ & $46.1 \pm 2.2$ & $46.41 \pm 0.14$ & $43.93 \pm 0.01$ & $98 \pm 5$ & $43.53 \pm 0.89$ & $97 \pm 5$ \\
$\mathbf{F e}\left(\mu \mathrm{g} \mathrm{g}^{-1}\right)$ & $1.78 \pm 0.10$ & $1.80 \pm 0.01$ & $1.74 \pm 0.09$ & $102 \pm 3$ & $1.69 \pm 0.02$ & $99 \pm 5$ \\
$\mathbf{C u}\left(\mu \mathrm{g} \mathrm{g}^{-1}\right)$ & $0.7 \pm 0.1$ & $0.618 \pm 0.003$ & $0.653 \pm 0.012$ & $98 \pm 5$ & $0.798 \pm 0.045$ & $103 \pm 3$ \\
$\mathbf{M n}\left(\mu \mathrm{g} \mathrm{g}^{-1}\right)$ & $0.26 \pm 0.06$ & $0.236 \pm 0.004$ & $0.303 \pm 0.002$ & $101 \pm 3$ & $0.291 \pm 0.051$ & $101 \pm 5$ \\
\hline
\end{tabular}


Table 2. Analytical parameters: Instrumental precision and limits of detection and quantification for both methods (slurry and acid digestion) expressed in terms of powder infant formula ( $\mu \mathrm{g} 100 \mathrm{~g}^{-1}$ powder as sold).

\begin{tabular}{|c|c|c|c|c|c|c|c|c|c|}
\hline & \multirow[t]{2}{*}{$\begin{array}{c}\text { Analytical } \\
\text { method }\end{array}$} & \multicolumn{4}{|c|}{ Slurry dispersion method } & \multicolumn{4}{|c|}{ Acid decomposition method } \\
\hline & & $\begin{array}{l}\text { Inf. form. } \\
\text { sample }\end{array}$ & $\begin{array}{c}R S D \\
\%\end{array}$ & $L O D$ & $L O Q$ & $\begin{array}{l}\text { Inf. form. } \\
\text { sample }\end{array}$ & $\begin{array}{c}R S D \\
\%\end{array}$ & $L O D$ & $L O Q$ \\
\hline \multirow[t]{2}{*}{ Ca } & FAAS & n.a. & & 860 & 2865 & $374.6 \pm 5.2^{a}$ & 1.33 & 198 & 660 \\
\hline & ICP OES & $365.0 \pm 2.4^{\mathrm{a}}$ & 0.65 & 400 & 1333 & $364.6 \pm 1.4^{\mathrm{a}}$ & 0.38 & 68 & 223 \\
\hline $\boldsymbol{P}$ & ICP OES & $223.4 \pm 1.9^{\mathrm{a}}$ & 0.85 & 653 & 2175 & $231.5 \pm 2.0^{\mathrm{a}}$ & 0.86 & 163 & 543 \\
\hline \multirow[t]{2}{*}{$M g$} & FAAS & n.a. & & 96 & 321 & $37.70 \pm 0.40^{\mathrm{a}}$ & 1.22 & 8 & 23 \\
\hline & ICP OES & $40.24 \pm 0.46^{\mathrm{a}}$ & 1.14 & 120 & 400 & $36.44 \pm 0.36^{\mathrm{a}}$ & 0.95 & 10 & 30 \\
\hline \multirow[t]{2}{*}{$Z n$} & FAAS & $4.22 \pm 0.07^{\mathrm{a}}$ & 1.66 & 147 & 490 & $4.02 \pm 0.03^{\mathrm{a}}$ & 0.75 & 5 & 13 \\
\hline & ICP OES & n.a. & & 100 & 334 & $4.01 \pm 0.02^{\mathrm{a}}$ & 0.50 & 50 & 163 \\
\hline \multirow[t]{2}{*}{$F e$} & FAAS & $6.23 \pm 0.16^{\mathrm{a}}$ & 2.56 & 50 & 165 & $6.02 \pm 0.13^{a}$ & 2.16 & 213 & 708 \\
\hline & ICP OES & n.a. & & 35 & 117 & $5.95 \pm 0.09^{a}$ & 1.61 & 8 & 25 \\
\hline \multirow[t]{2}{*}{$C u$} & FAAS & $340 \pm 8$ & 2.41 & 38 & 125 & $342 \pm 6$ & 1.80 & 30 & 103 \\
\hline & ICP OES & n.a. & & 6 & 19 & $300 \pm 5$ & 1.66 & 5 & 18 \\
\hline \multirow[t]{2}{*}{ Mn } & FAAS & $94 \pm 3$ & 3.96 & 19 & 64 & $104 \pm 2$ & 1.92 & 15 & 30 \\
\hline & ICP OES & n.a. & & 3 & 11 & $85 \pm 1$ & 1.10 & 0.8 & 2.7 \\
\hline
\end{tabular}

n.a.: not available

${ }^{a}$ concentration expressed in mg $100 \mathrm{~g}^{-1}$ powder infant formula 
Table 3. Mineral and trace elements contents (mean \pm s.d., expressed as $m g 100 \mathrm{~g}^{-1}$ ) in different types of infant formulae. Comparison of measured results by acid decomposition and slurry dispersion methods.

\begin{tabular}{|c|c|c|c|c|c|c|c|c|}
\hline \multirow[t]{2}{*}{ Elem. } & \multicolumn{2}{|c|}{ Starter formulae } & \multicolumn{2}{|c|}{ Follow-up formulae } & \multicolumn{2}{|c|}{ Preterm formulae } & \multicolumn{2}{|c|}{ Hypoallergenic formulae } \\
\hline & Acid digest. & Slurry & Acid digest. & Slurry & Acid digest. & Slurry & Acid digest. & Slurry \\
\hline Ca & $341.8 \pm 69.9$ & $314.8 \pm 65.3$ & $522.9 \pm 83.1$ & $519.9 \pm 75.7$ & $572.7 \pm 64.3$ & $443.0 \pm 84.1$ & $243.3 \pm 42.8$ & $262.0 \pm 118.4$ \\
\hline$M g$ & $34.6 \pm 7.6$ & $36.4 \pm 7.9$ & $48.9 \pm 5.2$ & $49.6 \pm 7.2$ & $46.2 \pm 2.7$ & $45.4 \pm 5.2$ & $39.0 \pm 11.5$ & $41.5 \pm 14.7$ \\
\hline $\mathrm{Fe}$ & $7.18 \pm 1.77$ & $6.97 \pm 1.85$ & $9.09 \pm 1.26$ & $8.21 \pm 1.61$ & $7.90 \pm 2.45$ & $7.41 \pm 2.71$ & $8.01 \pm 0.43$ & $6.91 \pm 1.44$ \\
\hline$Z n$ & $4.06 \pm 0.50$ & $3.94 \pm 0.35$ & $4.96 \pm 1.11$ & $4.81 \pm 1.09$ & $4.77 \pm 0.80$ & $4.74 \pm 0.54$ & $4.09 \pm 0.80$ & $3.94 \pm 0.63$ \\
\hline$M n^{*}$ & $77 \pm 73$ & $78 \pm 58$ & $91 \pm 108$ & $89 \pm 102$ & $47 \pm 22$ & $43 \pm 25$ & $66 \pm 50$ & $46 \pm 29$ \\
\hline
\end{tabular}

* concentration expressed $\mu \mathrm{g} 100 \mathrm{~g}^{-1}$ powder infant formula

\begin{tabular}{ccccccccc}
\hline Elem. & \multicolumn{2}{c}{ Avoid reg. formulae } & \multicolumn{2}{c}{ Lactose-free formulae } & \multicolumn{2}{c}{ Functional formulae } & \multicolumn{2}{c}{ Soya formulae } \\
& Acid digest. & Slurry & Acid digest. & Slurry & Acid digest. & Slurry & Acid digest. & Slurry \\
\hline $\boldsymbol{C a}$ & $350.9 \pm 87.9$ & $410.9 \pm 131.7$ & $294.5 \pm 87.3$ & $303.8 \pm 66.0$ & $318.7 \pm 55.6$ & $240.1 \pm 70.9$ & $402.0 \pm 89.2$ & $349.5 \pm 90.2$ \\
$\boldsymbol{P}$ & $401.0 \pm 93.1$ & $375.9 \pm 97.6$ & $289.7 \pm 68.8$ & $260.0 \pm 91.1$ & $405.8 \pm 118.7$ & $373.0 \pm 154.5$ & $297.5 \pm 76.8$ & $245.4 \pm 110.9$ \\
$\mathbf{M g}$ & $39.3 \pm 5.2$ & $43.6 \pm 9.3$ & $49.2 \pm 5.7$ & $52.3 \pm 8.6$ & $56.9 \pm 6.7$ & $58.4 \pm 8.8$ & $35.7 \pm 5.3$ & $37.1 \pm 4.3$ \\
$\mathbf{F e}$ & $9.52 \pm 1.35$ & $7.80 \pm 1.48$ & $6.48 \pm 1.96$ & $5.34 \pm 1.99$ & $7.04 \pm 3.44$ & $6.95 \pm 3.27$ & $7.93 \pm 2.98$ & $7.85 \pm 2.20$ \\
$\mathbf{Z n}$ & $4.42 \pm 0.91$ & $4.24 \pm 0.68$ & $3.46 \pm 0.86$ & $3.36 \pm 0.78$ & $4.10 \pm 0.93$ & $4.02 \pm 0.76$ & $5.20 \pm 1.04$ & $5.05 \pm 1.23$ \\
$\boldsymbol{C u}^{*}$ & $277 \pm 26$ & $247 \pm 30$ & $345 \pm 43$ & $325 \pm 49$ & $314 \pm 17$ & $293 \pm 31$ & $319 \pm 40$ & $326 \pm 45$ \\
$\mathbf{M n}^{*}$ & $62 \pm 15$ & $41 \pm 23$ & $179 \pm 104$ & $144 \pm 83$ & $41 \pm 17$ & $36 \pm 26$ & $304 \pm 50$ & $277 \pm 69$ \\
\hline
\end{tabular}

* concentration expressed $\mu \mathrm{g} 100 \mathrm{~g}^{-1}$ powder infant formula 

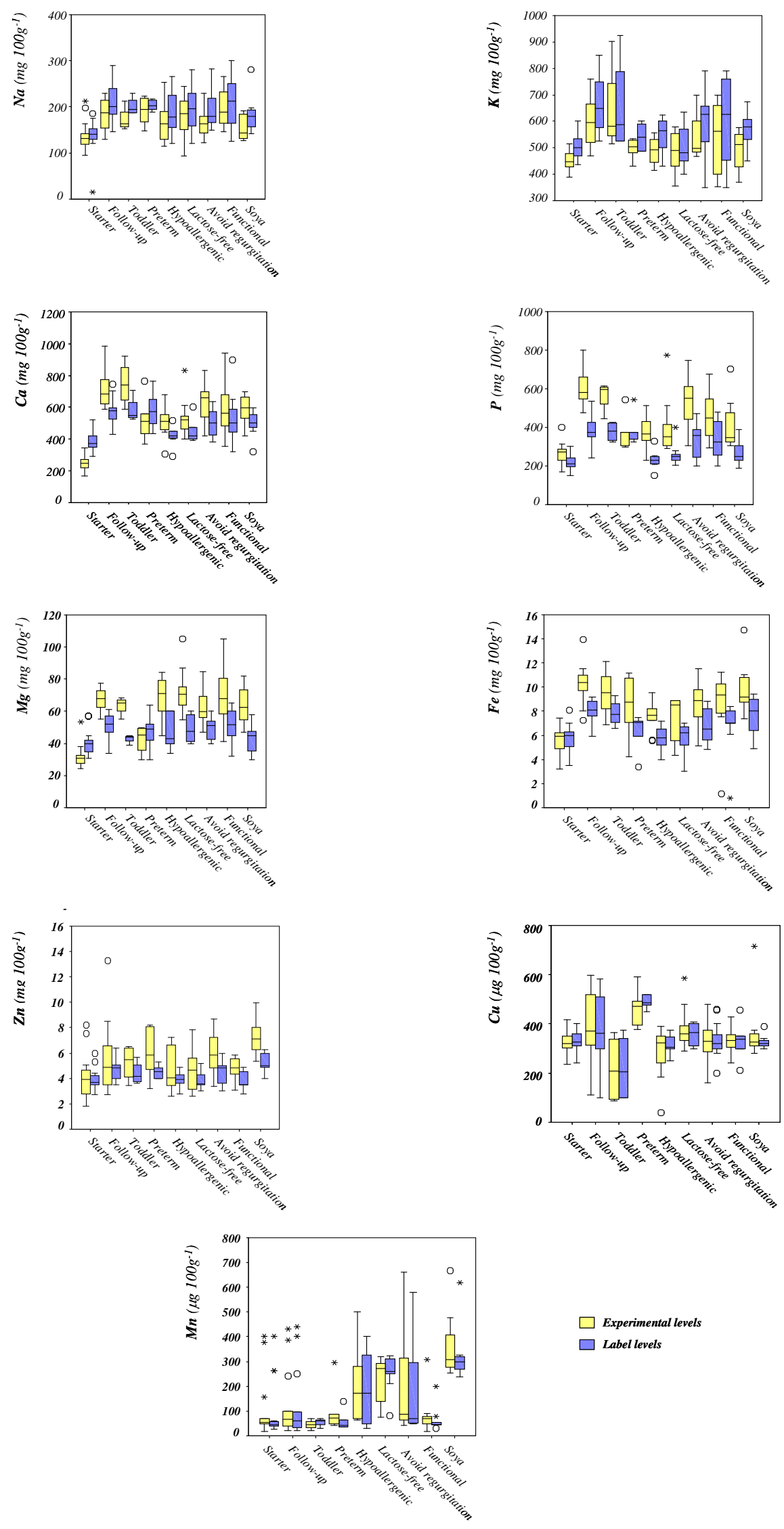

$\square$ Experimental levels

$\square$ Label levels 


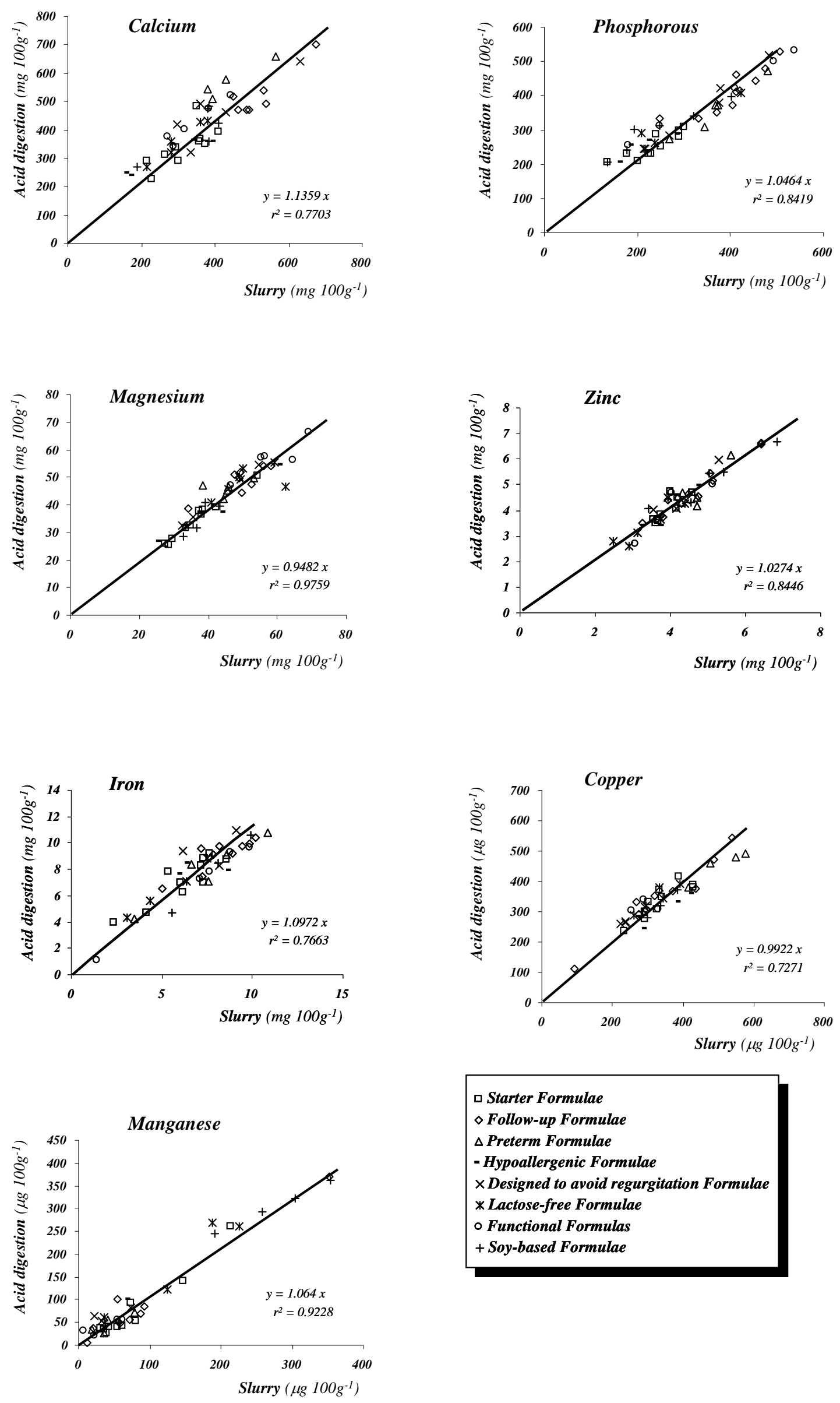

口 Starter Formulae

$\diamond$ Follow-up Formulae

$\triangle$ Preterm Formulae

- Hypoallergenic Formulae

$\times$ Designed to avoid regurgitation Formulae

* Lactose-free Formulae

- Functional Formulas

+ Soy-based Formulae 